\title{
Adaptação Transcultural da Versão Portuguesa do Social Support Appraisals para o Brasil
}

\author{
Cross-Cultural Adaptation of the Portuguese Version of Social Support \\ Appraisals for Brazil
}

\author{
Carolina Elisabeth Squassoni* \& Thelma Simões Matsukura \\ Universidade Federal de São Carlos, São Carlos, São Paulo, Brasil
}

\begin{abstract}
Resumo
Objetivo: apresentar o processo de adaptação transcultural da versão portuguesa do Social Support Appraisals e obter uma versão brasileira. Método: foram realizadas as avaliações de equivalência conceitual, itens, semântica, operacional, mensuração e funcional. Participaram 218 alunos da $4^{\mathrm{a}}$ à $8^{\mathrm{a}}$ série do ensino fundamental. Resultados: Na equivalência de mensuração a análise fatorial revelou quatro dimensões, o valor do coeficiente alfa para a escala total igual a 0,79 e a validade de construto demonstrou que quanto maior a idade e série escolar dos participantes maior a percepção do apoio dos amigos e menor a percepção do apoio dos professores. Conclusão: estudos futuros devem ser realizados com populações de diferentes regiões do país, a fim de observar a adequabilidade da versão brasileira.

Palavras-chave: Adaptação transcultural, apoio social, criança, adolescente.

Abstract

Objective: To present the process of cross-cultural adaptation of the Portuguese version of Social Support Appraisals. Method: The process of cross-cultural adaptation involved the evaluation of conceptual, items, semantics, operational, measurement and functional equivalence. Two hundred eighteen students from $4^{\text {th }}$ to $8^{\text {th }}$ grades participated in the study. Results: In measurement equivalence, factor analysis revealed four dimensions with values of alpha coefficient for the total scale of .79. The construct validity demonstrated that the greater the age and education level of the participants, the greater was the support perceived from friends and the lower the perception of teacher's support. Conclusion: further studies should be conducted with people from different regions of the country in order to observe the suitability of the Brazilian version.

Keywords: Cross-cultural adaptation, social support, child, adolescent.
\end{abstract}

A avaliação do apoio social percebido e/ou recebido por crianças e adolescentes e sua relação com variáveis relacionadas ao desenvolvimento tem sido alvo de estudos internacionais, que fazem uso de instrumentos validados para a investigação desse construto (Barrera, Fleming, \& Khan, 2004; Hagen, Myers, \& Mackintosh, 2005; Malecki \& Demaray, 2006). Na literatura nacional há

* Endereço para correspondência: Rua Humberto de Campos, 363, Vila Lutfalla, São Carlos, SP, Brasil 13570-670. E-mail: carolinasquassoni15@gmail.com e thelma@ufscar.br

As autoras agradecem à Fundação de Amparo à Pesquisa do Estado de São Paulo (FAPESP), por ter financiado este trabalho através da concessão de bolsa de estudo. Agradecem também aos autores do instrumento, ao prof. Allan Vaux e colaboradores, e as Profas. Ana Marie Fontaine e Cristina Antunes.

Agradecimentos especiais aos professores e especialistas que participaram do processo de adaptação transcultural. Este estudo faz parte da Dissertação de Mestrado de Carolina Elisabeth Squassoni sob a orientação de Thelma Simões Matsukura. pesquisas que envolvem avaliações diretas da percepção da criança e do adolescente sobre o apoio social (Ogido, 2011; Piccinini, Rapoport, Levandowski, \& Voigt, 2002; Poletto \& Koller, 2002; Siqueira, Betts, \& Dell'Aglio, 2006), porém os instrumentos utilizados não são validados ou não são específicos para a população de crianças e adolescentes.

Nos estudos de Poletto e Koller (2002) e de Siqueira et al. (2006) foram utilizados o Mapa dos Cinco Campos e entrevistas para avaliarem as redes de apoio social e afetivo de seus participantes, crianças e adolescentes, respectivamente. Embora usado para a avaliação do apoio social, o Mapa dos Cinco Campos não é específico para a população de crianças e adolescentes e entende-se que não se trata de um instrumento validado e normatizado. Já Ogido (2011) e Piccinini et al. (2002) fizeram uso de entrevistas.

A possibilidade de realização de estudos referentes à avaliação do apoio social, bem como sua influência para as crianças e adolescentes pode ter um importante valor 
preditivo para o desenvolvimento psicossocial dessa população, pois as relações estabelecidas com a família, amigos e escola influenciam o desenvolvimento psicológico e são importantes para cognição, competências e definição de um senso de si mesmo (Arriaga, Claudino, \& Cordeiro, 2005; Marturano, Elias, \& Campos, 2004; Pereira, Canavarro, Mendonça, \& Cardoso, 2005). A família é responsável pelo apoio físico, emocional, educacional e social de crianças e adolescentes, sendo responsável pelos cuidados e estímulos necessários ao crescimento e desenvolvimento infantil-juvenil (Bee, 1975/2008; Hutz, 2005).

Além do relacionamento familiar, no contexto escolar, as crianças e adolescentes podem ter a oportunidade de adquirir novas informações, desenvolver habilidades e fazer novos amigos, que passam a transferir os valores, atitudes e comportamentos que o jovem adota como orientadores das suas experiências e escolhas (Cordeiro, Arriaga, \& Claudino, 2006; Marturano et al., 2004).

Diante da inexistência de instrumentos de aferição do apoio social, validados e específicos para a população de crianças e adolescentes brasileiros, e diante da disponibilidade de instrumentos internacionais com estudos de confiabilidade e validade, este artigo apresenta, de acordo com o roteiro proposto por Herdman, Fox-Rushby e Badia (1998), o processo de adaptação transcultural da versão em língua portuguesa de Portugal do instrumento intitulado Social Support Appraisals - SSA (Antunes \& Fontaine, 1995) para a obtenção de uma versão brasileira. O roteiro de adaptação transcultural de Herdman et al. (1998) propõe a avaliação de seis equivalências distintas, divididas e nomeadas por equivalência conceitual, de itens, semântica, operacional, de mensuração e funcional.

A equivalência conceitual aborda a avaliação da pertinência dos conceitos e dimensões apreendidos pelo instrumento original na cultura alvo da nova versão. A equivalência de itens verifica a adequação de cada item do instrumento original (significados, sentidos e conceitos envolvidos), a fim de buscar a melhor representação desses itens para população onde será usada a nova versão do instrumento. Já a avaliação da equivalência semântica consiste na transferência de significados entre línguas, a fim de propiciar na população-alvo das duas culturas um efeito similar. Na equivalência operacional, verificam-se a viabilidade e a adequação de formato e modo de administração do instrumento junto à nova população, que se refere aos procedimentos de utilização, formato de administração, orientações e layout do instrumento original. A equivalência de mensuração avalia as propriedades psicométricas da nova versão e realiza a comparação entre os resultados das versões original e adaptada. Por fim, a equivalência funcional se dá com a verificação das etapas anteriores e sinaliza para o estabelecimento da nova versão adaptada (Herdman et al., 1998).

De origem americana, o SSA foi desenvolvido por Vaux et al. (1986) de acordo com as proposições de Cobb (1976), que definiu o apoio social como uma informação que levaria o indivíduo a acreditar que é amado, que as pessoas se preocupam com ele, que é apreciado, que o valorizam e que está afiliado a grupos com obrigações mútuas. Vaux (1988) ressalta que a avaliação do apoio social deve ser feita a partir da percepção da pessoa, fato considerado importante em todas as etapas do desenvolvimento humano, mas especialmente na fase da infância e adolescência, sobre a qual muitos estudos são realizados com base na avaliação dos pais ao responderem sobre o apoio social de seus filhos.

As avaliações psicométricas da versão original do SSA foram realizadas a partir de cinco amostras de estudantes e cinco amostras de pessoas da comunidade. $\mathrm{O}$ SSA demonstrou boa consistência interna obtendo índices de alfa de Cronbach derivados da aplicação da primeira amostra iguais a $0,90,0,80$ e 0,84 para o SSA total, família e amigos, respectivamente. Já na amostra de pessoas da comunidade os índices encontrados foram para SSA total igual a 0,90 , SSA família igual a 0,81 e 0,71 para amigos. Além disso, as subescalas apresentaram estabilidade satisfatória no intervalo de seis semanas, com correlação teste-reteste igual a 0,80 para SSA família e 0,71 para SSA amigos (Vaux et al., 1986). O estudo americano verificou também a validade convergente da escala a partir de associações positivas do SSA com outras sete medidas de percepção de apoio social, com variáveis de fontes de apoio, com medidas de bem estar psicológico e com fatores de personalidade (Vaux et al., 1986).

Antunes e Fontaine (1995) realizaram estudos de tradução, alargamento e verificação das qualidades psicométricas do SSA para a população de crianças e adolescentes de Portugal e acrescentaram 7 itens referentes à percepção do apoio social advindo dos professores, criando assim a subescala SSA professores. Na sua forma final, a versão portuguesa da escala é constituída por 30 itens divididos em 4 subescalas: família, amigos, professores e outros. Estas subescalas avaliam o grau em que uma pessoa se sente estimada, respeitada e envolvida pela família (subescala constituída por 8 itens: $3,6,9,16,19,22,25$ e 30), pelos amigos (7 itens: 1, 8, 11, 14, 17, 24 e 27), pelos professores (7 itens: $2,5,12,15,18,21$ e 28 ) e pelos outros em geral (8 itens: 4, 7, 10, 13, 20, 23, 26 e 29).

O SSA possui uma pequena introdução que contém informações sobre o conteúdo e os objetivos do instrumento, além de instruções para o seu preenchimento. No que diz respeito aos itens, esses são dispostos de forma alternada, com questões afirmativas e negativas. O SSA é uma escala do tipo likert, na qual as questões afirmativas recebem pontuação de seis pontos (Concordo Totalmente) a um ponto (Discordo Totalmente); nas questões negativas a pontuação é inversa. A partir da soma das pontuações são obtidos os valores referentes a cada subescala e somando-se os valores obtém-se a pontuação para o apoio social total. Assim, os valores para o apoio total variam do mínimo de 30 ao máximo de 180 , nas subescalas SSA-família e SSA-outros os valores variam de oito a 48, 
nas subescalas SSA-amigos e SSA-professores o valor mínimo é sete e o máximo é 42.

A versão portuguesa do instrumento foi submetida a estudos de fidedignidade a fim de determinar suas medidas psicométricas. Na aplicação do instrumento em uma amostra de 365 sujeitos, do $5^{\circ}$ ao $9^{\circ}$ ano de escolaridade, foram obtidos respectivamente para a escala total, subescalas amigos, família, professores e outros os valores de alfa de Cronbach iguais a $0,91,0,79,0,80,0,79$ e 0,72 (Antunes \& Fontaine, 1995). A análise fatorial confirmou a estrutura original proposta por Vaux, com três fatores (família, amigos e outras pessoas em geral) e a subescala professores se distinguiu das outras fontes de apoio (Antunes \& Fontaine, 1995). A validade de construto foi avaliada por meio das diferenças significativas obtidas em função das fontes de apoio e a partir da diferenciação da percepção do apoio em função do ano de escolaridade (Antunes \& Fontaine, 1995).

Optou-se pela versão de Portugal do SSA, pois a escala contempla a faixa etária pretendida; avalia o apoio social percebido das principais fontes, incluindo os professores; por possuir uma versão em português e apresentar características psicométricas satisfatórias; pelas vantagens de se utilizar instrumentos de medida já validados e pela possibilidade de comparação de resultados em populações diferentes. Após o exposto, é o objetivo deste estudo a apresentação do processo de adaptação transcultural do SSA para a Língua Portuguesa do Brasil e de uma versão para uso em estudos brasileiros que irão investigar a percepção do apoio social de crianças e adolescentes com faixa etária entre nove e dezoito anos.

\section{Método}

O presente estudo foi aprovado pelo Comitê de Ética em Pesquisa em Seres Humanos e seguiu as deliberações do Conselho Nacional de Saúde. Para uso das informações aqui apresentadas declara-se que todos os participantes e/ ou responsáveis assinaram o Termo de Consentimento Livre e Esclarecido. Ressalta-se que para o uso do SSA e adaptação para o Brasil houve consentimento dos autores da versão original e portuguesa.

\section{Participantes}

Participaram deste estudo 218 crianças e adolescentes com idades entre 9 e 18 anos, alunos da $4^{\mathrm{a}}$ à $8^{\mathrm{a}}$ série do ensino fundamental, matriculados em uma escola pública e em uma escola particular de uma cidade do interior do estado de São Paulo com população aproximada de 212.956 habitantes (Instituto Brasileiro de Geografia e Estatística [IBGE], 2007). Dos 218 participantes, oito participaram do pré-teste com a versão brasileira do SSA e 210 responderam à versão final da escala, suas respostas foram consideradas para a verificação da equivalência funcional e de mensuração do instrumento. Trata-se de uma amostra não probabilística, visto que o objetivo dessa etapa não consistia na representatividade, mas na avaliação da escala por meio dos coeficientes psicométricos.

\section{Procedimentos}

Avaliação da Equivalência Conceitual e de Itens. Essas avaliações foram realizadas pelo comitê de especialistas do desenvolvimento infantil, composto por um psiquiatra, três psicólogos e três terapeutas ocupacionais, cuja função foi a de explorar a bibliografia referente ao apoio social bem como aos estudos realizados com o SSA e verificar a pertinência dos itens da escala de acordo com as definições e conceitos que embasaram o construto na construção da escala original. Na equivalência de itens, o comitê avaliou-os de acordo com a proposta de adaptação para o novo contexto (Herdman, Fox-Rushby, \& Badia, 1998; Reichenheim \& Moraes, 2007). Para essas avaliações cada avaliador recebeu um formulário com o material bibliográfico e avaliou-o separadamente, sendo que posteriormente as respostas foram analisadas pelas autoras para a formatação final.

Avaliação da Equivalência Semântica. Teve por objetivo manter os significados e/ou sentidos dos principais conceitos do instrumento original em sua versão adaptada, buscando um mesmo entendimento em ambas as culturas (Herdman et al., 1998; Reichenheim \& Moraes, 2007). Ressalta-se que como o SSA estava em português não foi realizado o processo de tradução e retrotradução, sendo cumprido o procedimento de adequação do português. A fim de adquirir-se tal conformidade foram realizados: adequações do instrumento para o idioma da cultura-alvo, apreciação formal da equivalência semântica, revisão e pré-teste.

A adequação foi realizada por dois profissionais de nível superior com língua materna portuguesa brasileira e com vivências em Portugal. Ambos apresentaram, de forma independente, suas adequações do instrumento original para o português do Brasil, sendo os produtos dessa avaliação duas propostas de versões do SSA brasileiro. Na Tabela 1 são apresentados os itens da versão de Portugal do SSA.

A apreciação formal da equivalência semântica foi realizada por um profissional de nível superior formado em Letras, cuja tarefa foi comparar os significados gerais dos termos entre a versão original portuguesa e as duas propostas de adaptação realizadas para a versão brasileira. O objetivo dessa apreciação foi avaliar a pertinência e a aceitabilidade do estilo empregado ou o uso específico de determinada palavra na versão proposta do instrumento para a nova cultura-alvo (Herdman et al., 1998; Reichenheim \& Moraes, 2007).

Dessa forma, os itens foram comparados e selecionados de acordo com as opções de resposta que indicaram a menor alteração (inalterado, pouco alterado, muito alterado e completamente alterado). Além disso, o avaliador apresentou, quando necessário, propostas ou substituições referentes às versões apresentadas. 
Tabela 1

Itens da Versão de Portugal do SSA

Itens

1) Os meus amigos respeitam-me

2) Tenho professores que se preocupam bastante comigo

3) A minha família estima-me bastante

4) Eu não sou importante para os outros

5) Os meus professores estimam-me

6) A minha família preocupa-se bastante comigo

7) As pessoas, de um modo geral, gostam de mim

8) De forma geral, posso confiar nos meus amigos

9) Sou bastante admirado pelos meus familiares

10) Sou respeitado pela generalidade das pessoas

11) Os meus amigos não se preocupam nada comigo

12) Eu sou bastante apreciado pelos meus professores

13) As pessoas têm estima por mim

14) Sinto-me muito ligado aos meus amigos

15) Os meus professores confiam em mim

16) A minha família gosta muito de mim

17) Os meus amigos gostam de estar comigo

18) Na generalidade, não posso contar com os meus professores para me darem apoio

19) Os membros da minha família confiam em mim

20) Sinto que as pessoas, de um modo geral, me apreciam

21) A maioria dos meus professores respeita-me muito

22) Não posso contar com a minha família para me dar apoio

23) Sinto-me bem quando estou com outras pessoas

24) Eu e os meus amigos somos muito importantes uns para os outros

25) A minha família respeita-me muito

26) Sinto que as pessoas me dão valor

27) Eu e os meus amigos temo-nos ajudado imenso uns aos outros

28) Não me sinto muito chegado aos meus professores

29) Se eu amanhã morresse, poucas pessoas teriam saudades de mim

30) Não me sinto muito ligado à minha família.

A revisão envolveu o comitê de especialistas na identificação de problemas de cada uma das atividades anteriores. Coube aos membros do comitê verificar a correspondência literal entre os itens da versão portuguesa e da brasileira, além da adequação dos itens da versão brasileira de acordo com a faixa etária e contexto cultural da população alvo do estudo. A partir da revisão, formou-se a versão síntese do SSA, composta por itens de uma das duas versões que apresentaram concordância superior a $80 \%$ ou por itens que apresentaram sugestões de alterações consideradas adequadas.

O pré-teste foi realizado junto a oito crianças e adolescentes, alunos do $4^{\circ}$ ao $8^{\circ}$ ano do ensino fundamental, cujo objetivo foi verificar a aceitabilidade e compreensão da versão síntese do SSA. Solicitou-se aos participantes que respondessem a cada item da escala, sendo apontadas dúvidas e dificuldades no entendimento das instruções e na apresentação dos itens. Em seguida, requereram-se sugestões, sinônimos e expressões que, em substituição às questões problemáticas, possibilitariam um maior entendimento por parte dos respondentes.

Avaliação da Equivalência Operacional. Nessa etapa estabeleceu-se a viabilidade e adequação de formato e modo de administração do instrumento junto à nova população (Herdman et al., 1998; Reichenheim \& Moraes, 2007). Para a avaliação da equivalência operacional utilizou-se 
no pré-teste o modelo de administração e formatação da versão portuguesa do SSA e, a partir disso, verificou-se sua viabilidade na aplicação da versão brasileira.

Avaliação da Equivalência de Mensuração. Consistiu em avaliar as medidas de confiabilidade e validade da versão brasileira do SSA, comparando-as com as encontradas na versão de Portugal. Foram apreciadas: a consistência interna, por meio do coeficiente alfa de Cronbach; a estrutura fatorial com rotação variamax e extração de autovalores maiores que 1; e a validade de construto, por meio de análises de variância, que buscaram as possíveis relações entre o sexo, a idade e a série dos participantes no que diz respeito à percepção do apoio da família, dos amigos, dos professores e outros, a fim de verificar a pertinência dos resultados com o quadro teórico do construto.

\section{Resultados}

\section{Avaliação da Equivalência Conceitual e de Itens}

A discussão do grupo de especialistas e a revisão bibliográfica sugeriram que os conceitos relacionados ao apoio social e utilizados na elaboração do instrumento eram igualmente relevantes nas culturas portuguesa e brasileira. Além disso, os itens foram avaliados como adequados, considerando as dimensões percepção e fontes de apoio.

\section{Avaliação da Equivalência Semântica}

Nas adequações do instrumento, ao serem avaliadas as duas versões propostas pelos dois profissionais que participaram dessa etapa, verificou-se concordância entre ambos ao considerarem que cinco dos 30 itens da versão portuguesa não necessitavam de alterações para a formação da versão brasileira. Da mesma forma, esses profissionais concordaram que era necessária a adequação de 14 itens da versão portuguesa e apresentaram sugestões de modificações para esses itens. Nos 11 itens restantes não houve concordância entre os profissionais. No caso em que o item foi considerado inadequado, foram feitas sugestões para sua adequação. Por outro lado, quando o item foi avaliado como adequado não houve proposta de alteração. Na Tabela 2 são apresentadas as duas propostas de adequações, A1 foi apresentada pelo profissional 1 e A2 pelo profissional 2.

Tabela 2

Adequação do SSA para o Brasil

\begin{tabular}{|c|c|c|}
\hline Item & Adaptação 1: versão A1 & Adaptação 2: versão A2 \\
\hline 1 & Os meus amigos me respeitam & Idem A1 \\
\hline 2 & Sem alteração & Sem alteração \\
\hline 3 & A minha família gosta muito de mim & Eu sou bastante querido pela minha família \\
\hline 4 & Eu não me considero importante para os outros & Sem alteração \\
\hline 5 & Os meus professores gostam de mim & Eu me sinto querido pelos meus professores \\
\hline 6 & A minha família se preocupa bastante comigo & Sem alteração \\
\hline 7 & Sem alteração & As pessoas gostam de mim \\
\hline 8 & De maneira geral, posso confiar nos meus amigos & Posso confiar nos meus amigos \\
\hline 9 & Sem alteração & Sou muito admirado pelos meus familiares \\
\hline 10 & Sou respeitado pelas pessoas em geral & Sou respeitado pelas pessoas \\
\hline 11 & $\begin{array}{l}\text { Os meus amigos não se preocupam nem um pouco } \\
\text { comigo }\end{array}$ & Os meus amigos não se preocupam comigo \\
\hline 12 & Eu sou muito valorizado pelos meus professores & Eu sou admirado pelos meus professores \\
\hline 13 & As pessoas gostam de mim & As pessoas gostam de mim \\
\hline 14 & Eu me sinto muito ligado aos meus amigos & Sem alteração \\
\hline 15 & Sem alteração & Sem alteração \\
\hline 16 & A minha família me quer muito & Sem alteração \\
\hline 17 & Sem alteração & Sem alteração \\
\hline 18 & $\begin{array}{l}\text { No geral, não posso contar com os meus professores para } \\
\text { me darem apoio }\end{array}$ & $\begin{array}{l}\text { Não posso contar com os meus professores } \\
\text { para me apoiar }\end{array}$ \\
\hline 19 & O pessoal da minha família confia em mim & A minha família confia em mim \\
\hline 20 & Sinto que as pessoas, de um modo geral me valorizam & $\begin{array}{l}\text { Geralmente as pessoas demonstram } \\
\text { admiração por mim }\end{array}$ \\
\hline
\end{tabular}


21 A maioria dos meus professores me respeita muito

22 Sem alteração

23 Eu me sinto bem quando estou com outras pessoas

24 Eu e meus amigos somos de muito valor uns para os outros

25 A minha família me respeita muito

26 Sem alteração

27 Eu e meus amigos costumamos a nos ajudar demais uns aos outros

28 Sem alteração

29 Se eu morresse amanhã poucas pessoas sentiriam minha falta

30 Eu me considero pouco ligado à minha família
Sem alteração

Sem alteração

Sem alteração

Sem alteração

Sou muito respeitado pela minha família

Sem alteração

Eu e meus amigos nos ajudamos muito

Não me sinto muito próximo aos meus professores

Sem alteração

Não me sinto muito próximo da minha família
No passo seguinte, o profissional formado em Letras realizou a apreciação da equivalência semântica, na qual foram avaliadas as duas adequações e mantiveram-se no elenco da versão brasileira os itens considerados inalterados ou com a menor sugestão de alteração, considerando os aspectos semânticos. No item 1, sugeriu-se a mesma adequação nas duas versões, e A1 e A2 foram consideradas inalteradas; no item 2 não houve alteração com relação ao original; no item 3, optou-se pela versão A2; no item 4 não houve alteração com o original; nos itens 5 e 6, optou-se pelas versões A1; no item 7 a versão de A2 foi considerada completamente alterada, pois na versão portuguesa o aposto "de modo geral" significa que a maior parte gosta dele (sujeito da pesquisa), mas não todos, o que fica subentendido que existem alguns que não gostam; no item 8 a versão $\mathrm{A} 2$ foi considerada completamente alterada, pois retirando o "de forma geral" muda-se o sentido da oração, uma vez que essa expressão indica que ele pode confiar na maioria dos amigos, mas não em todos; no item 9 a versão A2 foi considerada mais adequada; no item 10 a versão $\mathrm{A} 2$ foi considerada completamente alterada, pois ao retirar a generalidade ou seu sinônimo muda-se a semântica da oração, visto que ele (sujeito da pesquisa) não é respeitado por todas as pessoas, mas sim pela maioria; no item 11 a versão A1 foi considerada inalterada; no item 12, sugeriu-se acrescentar o advérbio "muito" para que A2 ficasse inalterada; no item 13 as versões A1 e A2 foram consideradas inalteradas; no item 14 a versão A1 foi considerada mais adequada; no item 15 as versões A1 e A2 foram consideradas inalteradas; no item 16 a A1 foi considerada completamente alterada, pois "querer" é diferente de "gostar"; no item 17, sugeriu-se a mesma adequação nas duas versões e A1 e A2 foram consideradas inalteradas; em 18 a versão A1 foi avaliada como mais adequada; no item 19, sugeriu-se o uso de A1; no item 20 a versão A1 foi avaliada como pouco alterada; no item 21 a versão A1 foi considerada inalterada e mais adequada; no item 22 não houve alteração com a versão de Portugal; a versão A1 foi considerada inalterada e mais adequada para o item 23; em 24 a versão A2 foi considerada inalterada e mais adequada; no item 25 a versão $\mathrm{A} 1$ mostrou-se mais adequada; no item 26 , sugeriu-se a mesma adequação nas duas versões e A1 e A2 foram consideradas inalteradas; em 27 e 28 a versão A2 mostrou-se mais adequada; no item 29 a versão A1 foi considerada mais adequada; por fim, no item 30 a versão $\mathrm{A} 2$ foi considerada completamente alterada, pois o verbo "considerar" é diferente semanticamente do verbo "sentir".

De posse dos itens considerados pelo profissional, obteve-se uma versão síntese do SSA. Em seguida, o processo de revisão foi realizado pelo comitê de especialistas que, de posse da versão síntese, verificou a correspondência de significado referencial entre as versões portuguesa e brasileira e a adequabilidade da versão adaptada para a população do estudo. Nessa apreciação 20 itens apresentaram a concordância de $100 \%$, sendo que para os itens 19 e 29 foram apresentadas pequenas sugestões de alteração.

Os dez itens restantes apresentaram a concordância superior a $80 \%$. Desses, os itens $11,12,27,28$ e 30 receberam pequenas sugestões para adequação. As sugestões feitas pelo comitê de especialistas foram acatadas e, a partir dessa apreciação, formou-se a versão brasileira do SSA para a aplicação no pré-teste. A partir da aplicação no pré-teste verificou-se que a versão brasileira foi compreendida e bem aceita linguisticamente e culturalmente na amostra avaliada.

\section{Avaliação da Equivalência Operacional}

Considerou-se adequada a aplicação autopreenchível da versão brasileira no mesmo formato e administração da versão portuguesa, mantendo-se o mesmo número de questões e as mesmas opções de respostas que o SSA de Portugal. Ressalta-se que um profissional treinado deve acompanhar a aplicação da escala. 
Tabela 3

Versão Brasileira do SSA Usada no Pré-teste

Versão brasileira do SSA

1) Os meus amigos me respeitam

2) Tenho professores que se preocupam bastante comigo

3) Eu sou bastante querido pela minha família

4) Eu não sou importante para os outros

5) Os meus professores gostam de mim

6) A minha família se preocupa bastante comigo

7) As pessoas, de um modo geral, gostam de mim

8) De maneira geral, posso confiar nos meus amigos

9) Sou bastante admirado pelos meus familiares

10) Sou respeitado pelas pessoas em geral

11) Os meus amigos não se preocupam nada comigo

12) Meus professores me admiram bastante

13) Eu sou querido pelas pessoas

14) Eu me sinto muito ligado aos meus amigos

15) Os meus professores confiam em mim

16) A minha família gosta muito de mim

17) Os meus amigos gostam de estar comigo

18) No geral, não posso contar com os meus professores para me darem apoio

19) As pessoas de minha família confiam em mim

20) Sinto que as pessoas, de um modo geral, me admiram

21) A maioria dos meus professores me respeita muito

22) Não posso contar com a minha família para me dar apoio

23) $\mathrm{Eu}$ me sinto bem quando estou com outras pessoas

24) Eu e os meus amigos somos muito importantes uns para os outros

25) A minha família me respeita muito

26) Sinto que as pessoas me dão valor

27) Eu ajudo meus amigos e eles me ajudam

28) Não me sinto muito ligado aos meus professores

29) Se eu morresse amanhã poucas pessoas sentiriam saudades de mim

30) Não me sinto muito ligado a minha família

\section{Avaliação da Equivalência de Mensuração}

São apresentados os resultados obtidos a partir do indicador da consistência interna da escala, o Alfa de Cronbach. Para a categorização dos resultados utilizou-se o sistema proposto por Byrant (2000), cujas interpretações dos índices são: "Inadequado" para alfa menor que 0,49 ; "Adequado" para alfa entre 0,50 e 0,69; "Bom" para valores entre 0,70 e 0,79; "Muito Bom" para valores entre 0,80 e 0,89 ; e "Excelente" quando superior a 0,89 . A Tabela 4 apresenta os resultados de alfa e as respectivas classificações para a versão brasileira do SSA.

Tabela 4

Consistência Interna da Versão Brasileira do SSA

\begin{tabular}{lcc}
\hline Versão brasileira do SSA & Valores de alfa & Interpretações de Byrant (2000) \\
\hline Escala geral & 0,74 & Bom \\
Subescala Família & 0,57 & Adequado \\
Subescala Amigos & 0,72 & Bom \\
Subescala Professores & 0,79 & Bom \\
Subescala Outros & 0,61 & Adequado \\
\hline
\end{tabular}


Verifica-se na Tabela 4 que a subescala família apresentou índice de consistência interna baixo, porém considerado adequado. Dada essa informação, apresenta-se na Tabela 5 a estrutura fatorial da versão brasileira do SSA.
A Tabela apresenta na primeira coluna as subescalas do SSA e na segunda coluna os itens correspondentes a cada subescala. Os valores significativos obtidos com a análise fatorial de cada item são dispostos da terceira à sexta coluna (fatores 1, 2, 3 e 4 ).

Tabela 5

Estrutura Fatorial do SSA

\begin{tabular}{|c|c|c|c|c|c|c|}
\hline Subescala & Item & Fator 1 & Fator 2 & Fator 3 & Fator 4 & Comunalidade \\
\hline Professor & 12 & 0,86 & - & - & - & 0,77 \\
\hline Professor & 21 & 0,85 & - & - & - & 0,77 \\
\hline Professor & 5 & 0,83 & - & - & - & 0,71 \\
\hline Professor & 15 & 0,80 & - & - & - & 0,71 \\
\hline Professor & 2 & 0,76 & - & - & - & 0,64 \\
\hline Professor & 28 & 0,67 & - & - & - & 0,55 \\
\hline Professor & 18 & 0,64 & - & - & - & 0,43 \\
\hline Família & 6 & - & 0,79 & - & - & 0,67 \\
\hline Família & 3 & - & 0,75 & - & - & 0,63 \\
\hline Família & 16 & - & 0,71 & - & - & 0,62 \\
\hline Família & 25 & - & 0,62 & - & - & 0,64 \\
\hline Amigos & 14 & - & 0,55 & - & - & 0,54 \\
\hline Família & 9 & - & 0,52 & - & - & 0,53 \\
\hline Amigos & 24 & - & 0,51 & - & - & 0,50 \\
\hline Família & 19 & - & 0,49 & - & - & 0,54 \\
\hline Outros & 20 & - & - & 0,74 & - & 0,65 \\
\hline Outros & 13 & - & - & 0,71 & - & 0,58 \\
\hline Outros & 7 & - & - & 0,65 & - & 0,49 \\
\hline Outros & 26 & - & - & 0,60 & - & 0,46 \\
\hline Outros & 10 & - & - & 0,52 & - & 0,63 \\
\hline Família & 30 & - & - & 0,46 & - & 0,32 \\
\hline Outros & 29 & - & - & 0,45 & - & 0,29 \\
\hline Família & 22 & - & - & 0,45 & - & 0,28 \\
\hline Outros & 4 & - & - & 0,35 & - & 0,18 \\
\hline Outros & 23 & - & - & 0,40 & - & 0,30 \\
\hline Amigos & 1 & - & - & - & 0,72 & 0,53 \\
\hline Amigos & 27 & - & - & - & 0,71 & 0,60 \\
\hline Amigos & 17 & - & - & - & 0,68 & 0,63 \\
\hline Amigos & 8 & - & - & - & 0,61 & 0,49 \\
\hline Amigos & 11 & - & - & - & 0,54 & 0,30 \\
\hline \% Variância & & 28,89 & 13,09 & 5,82 & 5,44 & \\
\hline
\end{tabular}

Nota. (-) Valores não significativos. 
Verifica-se na Tabela 5 a extração de quatro fatores, fato que confirmou a existência das quatro dimensões, assim como na versão portuguesa. O primeiro fator corresponde à subescala professor, o segundo corresponde à família, o terceiro à subescala outros e o quarto e último fator corresponde à subescala amigos. Além disso, verificou-se nessa análise a existência de alguns itens que não se encontram em seu fator correspondente, como os itens 14 e 24 , que são itens da subescala amigos, mas encontram-se no segundo fator; e os itens 22 e 30, que correspondem à subescala "família", mas foram explicados no terceiro fator.

A seguir serão apresentados na Tabela 6 os resultados referentes à Análise de Variância, que teve como objetivo aferir e verificar a significância das diferenças e semelhanças sobre os efeitos do sexo, a idade e a série nas subescalas do SSA. Ressalta-se que foram realizados testes de normalidade em todos os modelos usados, o que permite a validade da análise.

Tabela 6

Análise de Variância $(N=210)$

\begin{tabular}{ccccccc}
\hline \multirow{2}{*}{ Subescala } & \multicolumn{2}{c}{ Série*Sexo } & \multicolumn{2}{c}{ Idade*Sexo } & \multicolumn{2}{c}{ Idade*Série } \\
\cline { 2 - 6 } & $F$ & $p$ & $F$ & $p$ & $F$ & $p$ \\
\hline Família & - & - & - & - & - & - \\
Amigos & 2,55 & 0,041 & - & - & 2,33 & 0,005 \\
Professores & 4,48 & 0,002 & - & - & 2,59 & 0,002 \\
Outros & 3,04 & 0,005 & - & - & - & - \\
\hline
\end{tabular}

Na Tabela 6 verifica-se o efeito significativo das interações entre série e sexo nas subescalas amigos, professores e outros, e entre idade e série na subescala amigos e professores. Testes de comparações múltiplas foram realizados a fim de verificar tais associações. Dentre os resultados significativos, verificou-se na subescala amigos (sexo e idade) que as meninas da $7^{\text {a }}$ série possuem em média uma percepção menor do apoio dos amigos em relação aos meninos e às meninas da $8^{\mathrm{a}}$ série. Já na relação entre idade e série para a mesma fonte de apoio, observou-se que os adolescentes de 14 anos apresentam em média uma menor percepção do apoio dos amigos quando comparados com os adolescentes de 15 e 17 anos da $8^{\mathrm{a}}$ série.

Com relação ao professor (sexo e série), verificou-se que as meninas da $6^{\mathrm{a}}$ série apresentam maior percepção do apoio em comparação aos meninos e às meninas da $7^{\mathrm{a}}$ série; já as meninas da $7^{\mathrm{a}}$ série possuem uma percepção do apoio dos professores maior que a apresentada pelos meninos e meninas da $8^{\mathrm{a}}$ série. No que diz respeito a idade e série, observou-se que há uma diminuição da percepção do apoio social advindo dos professores em função da idade, dos 11 aos 17 anos, e em função da série escolar, da $5^{\mathrm{a}}$ à $8^{\mathrm{a}}$ série.

\section{Avaliação da Equivalência Funcional}

Todo o processo foi revisto e avaliado como adequado. Porém sugere-se que novos estudos possam ser realizados na equivalência de mensuração, para verificar a adequação da versão brasileira de forma mais efetiva a partir de novas análises e com outras populações.

\section{Discussão e Considerações Finais}

Os conceitos que envolvem a construção do instrumento foram considerados representativos do construto, as adaptações realizadas foram culturalmente pertinentes $\mathrm{e}$ os itens foram considerados adequados no que diz respeito à capacidade de avaliar o construto na população-alvo. No que diz respeito às propriedades psicométricas, verifica-se que as versões portuguesa e americana apresentaram um melhor índice de consistência interna do que o obtido pela versão brasileira. Hipotetiza-se que tal resultado se deve ao fato da verificação da consistência interna da versão brasileira ter sido realizada com um menor número de participantes em comparação com os estudos português e americano, o que pode ter influenciado nos valores obtidos.

No que diz respeito à estrutura dimensional, a versão brasileira permitiu a distinção entre a percepção das quatro fontes, o que confirmou a estrutura do SSA de Portugal. No que diz respeito à validade de construto, foram observadas interações entre série e sexo nas subescalas amigos, professores e outros, e entre idade e série na percepção do apoio recebido dos amigos e professores. Em Portugal foram observadas diferenças na percepção do apoio em função do ano de escolaridade e da idade dos participantes. Com relação às fontes de apoio, verificou-se com relação aos professores, nos dois estudos, que a percepção desse suporte diminui conforme aumenta a idade e a série dos jovens. Tal fato corrobora com a literatura (Chagas, Aspesi, \& Fleith, 2005), pois, devido ao aumento das disciplinas escolares e consequentemente do número de 
professores há uma diminuição do tempo de contato com o professor, o que pode gerar uma menor percepção desse apoio. Além disso, há a presença de divergências entre o comportamento de ambos, pois, com o aumento da idade, os alunos tendem a ter atitudes de maior independência e autonomia e, por outro lado, os professores podem manter atitudes controladoras e autoritárias. Em relação, à percepção do suporte dos amigos, verifica-se que, em média, essa percepção cresce conforme aumenta a série escolar dos participantes. Tais resultados estão de acordo com a literatura (Moreno, 2004; Oliva, 2004) que apontam que na adolescência os jovens passam a interagir de forma significativa com os amigos, com quem passam a ter mais afinidades e a compartilhar experiências.

Considera-se que para estudos futuros com o SSA possam ser realizadas novas investigações com populações de diferentes regiões do país, a fim de observar a adequabilidade da versão brasileira e investigar a influência de variáveis relacionadas ao desenvolvimento humano na percepção do apoio social.

De toda forma, ressalta-se que a versão brasileira do SSA é o primeiro instrumento adaptado para o português brasileiro que permite que as próprias crianças e adolescentes avaliem o apoio social recebido, fato que contribuirá para o desenvolvimento de novas pesquisas na área.

\section{Referências}

Antunes, C., \& Fontaine, A. M. (1995). Diferenças na percepção de apoio social na adolescência: Adaptação do Social Support Appraisals. Cadernos de Consulta Psicológica, 10-11. Recuperado em 26 de janeiro, 2012, de http://repositorio-aberto. up.pt/bitstream/10216/15578/2/245.pdf

Arriaga, M., Claudino, J., \& Cordeiro, R. (2005). Suporte social e comportamentos aditivos em adolescentes pré-universitários. Revista Iberoamericana de Educação, 36(11). Recuperado em 26 de janeiro, 2012, de http://rieoei.org/ investigacion/1052Arriaga.pdf

Barrera, M., Fleming, C. F., \& Khan, F. S. (2004). The role of emotional social support in the psychological adjustment of siblings of children with cancer. Child: Care, Health and Development, 30, 103-111.

Bee, H. L. (2008). A criança em desenvolvimento (M. A. V. Veronese, Trad.). Porto Alegre, RS: Artmed. (Original publicado em 1975)

Byrant, F. B. (2000). Assessing the validity of measurement. In L. G. Grimm \& P. R. Yarnold (Eds.), Reading and understanding more multivariate statistics (pp. 94-146). Washington, DC: American Psychological Association.

Chagas, J. F., Aspesi, C. C., \& Fleith, D. S. (2005). A relação entre criminalidade e desenvolvimento: Uma visão sistêmica. In M. A. Dessen \& A. L. Costa Júnior, A ciência do desenvolvimento humano: Tendências atuais e perspectivas futuras (pp. 210-228). Porto Alegre, RS: Artmed.

Cobb, S. (1976). Social support as a moderator of life stress. Psychosomatic Medicine, 38(5), 300-314.

Cordeiro, R., Arriaga, M., \& Claudino, J. (2006). Depressão e suporte social em adolescentes e jovens adultos: Um estudo realizado junto de adolescentes pré-universitários. Revista Iberoamericana de Educación, 39(6), 185-196.
Hagen, K. A., Myers, B. J., \& Mackintosh, V. H. (2005). Hope, social support, and behavioral problems in at-risk children. American Journal of Orthopsychiatry, 75, 211-219.

Herdman, M., Fox-Rushby, J., \& Badia, X. (1998). A model of equivalence in the cultural adaptation of HRQoL instruments: The universalist approach. Quality of Life Research, 7(4), 323-335.

Hutz, C. S. (2005). Violência e risco na infância e adolescência: Pesquisa e intervenção. São Paulo, SP: Casa do Psicólogo.

Instituto Brasileiro de Geografia e Estatística. (2007). Contagem da população. Recuperado em 11 de setembro, 2008, de http:// www.ibge.gov.br/home/estatistica/populacao/contagem2007/ popmunic2007layoutTCU14112007.xls

Malecki, C. K., \& Demaray, M. (2006). Social support as a buffer in the relationship between socioeconomic status and academic performance. School Psychology Quarterly, 21(4), 375-395.

Marturano, E. M., Elias, L., \& Campos, M. (2004). O percurso entre a meninice e a adolescência: Mecanismos de vulnerabilidade e proteção. In E. M. Marturano, M. B. M. Linhares, \& S. R. Loureiro (Eds.), Vulnerabilidade e proteção: Indicadores na trajetória de desenvolvimento escolar (pp. 251-288). São Paulo, SP: Casa do Psicólogo.

Moreno, M. C. (2004). Desenvolvimento e conduta social dos seis anos até a adolescência. In C. Coll, A. Marchesi, \& A. Palácios (Eds.), Desenvolvimento psicológico e educação (2. ed., pp. 287-305). Porto Alegre, RS: Artemed.

Ogido, R. (2011). Adolescência, maternidade e mercado de trabalho: Uma relação em construção (Tese de doutorado, Faculdade de Saúde Pública, Universidade de São Paulo, SP, Brasil).

Oliva, A. (2004). Desenvolvimento social durante a adolescência. In C. Coll, A. Marchesi, \& A. Palácios (Eds.), Desenvolvimento psicológico e educação (2. ed., pp. 350-367). Porto Alegre, RS: Artemed.

Pereira, A. I. F., Canavarro, M. C., Mendonça, D. V., \& Cardoso, M. F. (2005). Validação de um instrumento de avaliação do apoio social em crianças - A versão portuguesa do " $M y$ family and friends". Revista Ibero Americana de Diagnóstico y Evaluación, 20(2), 105-131.

Piccinini, C. A., Rapoport, A., Levandowski, D. C., \& Voigt, P. R. (2002). Apoio social percebido por mães adolescentes e adultas: Da gestação ao terceiro mês de vida do bebê. Psico, 33(1), 9-35.

Poletto, R. C., \& Koller, S. H. (2002). Rede de apoio social e afetivo de crianças em situação de pobreza. Psico, 33, 151-176.

Reichenheim, M. E., \& Moraes, C. L. (2007). Operacionalização de adaptação transcultural de instrumentos de aferição usados em epidemiologia. Revista de Saúde Pública, 41(4), 665-673.

Siqueira, A. C., Betts, M. K., \& Dell'Aglio, D. D. (2006). Rede de apoio social e afetivo de adolescentes institucionalizados no sul do Brasil. Interamerican Journal of Psycology, 40(2), $149-158$.

Vaux, A. (1988). Social support: Theory, research, and intervention. New York: Praeger.

Vaux, A., Philips, J., Holly, L., Thompson, B., Williams, D., \& Stewart, D. (1986). The social support appraisals (SSA) scale: Studies of reliability and validity. American Journal of Community Psychology, 14, 195-220.

Recebido: 30/01/2012 $1^{a}$ revisão: $21 / 09 / 2012$ Aceite final: 13/12/2012 